\title{
Quantitative VLF data interpretation
}

\section{DAVID BEAMISH}

Beamish, D., 2000. Quantitative VLF data interpretation. Journal of Applied Geophysics, 45, 33-47.

DOI: $\underline{\text { 10.1016/S0926-9851(00)00017-3 }}$

British Geological Survey, Keyworth, Nottingham NG12 5GG, U.K.

\begin{abstract}
The ability of the VLF-R (Resistivity) method to provide quantitative subsurface resistivity information is examined. The frequencies used in conventional VLF (15 to $30 \mathrm{kHz}$ ) provide the deepest penetrations of the multi-frequency, extended method of RadioMT. Both methods are considered. VLF data, being effectively single frequency, are insufficient to resolve 1D (vertical) structure in any detail. At the site investigation scale, however, it is the departures from the background (vertically uniform) structure that are of interest. Improved methodologies for the quantitative assessment of VLF data derive from advances in regularised inversion techniques. Hydrogeological and waste-site examples of VLF-R survey data, aided by wide-band (VLF/RadioMT) synthetic modelling and inversion studies, are used to illustrate their shallow (0 to $20 \mathrm{~m}$ ) resolution capabilities in conductive environments.
\end{abstract}

\section{INTRODUCTION}

The plane-wave, VLF technique conventionally operates in the frequency range from 15 to $30 \mathrm{kHz}$. Keller and Frischknecht (1966) discuss radio wave geophysical methods prior to the introduction of the first commercial VLF instrument in 1964. The VLF method was first developed as an inductive sounding technique measuring the amplitude (and subsequently phase) relationship between the vertical (secondary) magnetic field $\mathrm{Z}$ relative to the horizontal primary field $\mathrm{H}$. This method, referred to here as VLF-Z (elsewhere as VLF-EM), relies on wavefield interaction with two dimensional (2D) and three dimensional (3D) resistivity structure. The technique has since been extended to include a measure of the induced horizontal electric field component E. This VLF-R measurement provides a surface impedance value (e.g. E/H), usually expressed as apparent resistivity and phase, using short (e.g. $5 \mathrm{~m}$ ) electric dipoles. 
The methods, conventionally used for mineral and hydrogeological investigations, have been applied to a number of environmental problems (McNew and Arav, 1995; Benson et al., 1997). Typically only limited quantitative use is made of the data since it is perceived that the modelling of single frequency VLF-R is not warranted. The purpose of the present paper is to demonstrate the degree to which quantitative resistivity information can be obtained from VLF-R data in the context of detailed site assessment.

The source fields used are line spectra provided by military communication installations. Global scale signal strength contour maps for a number of important transmitters are given by McNeill and Labson (1991). The VLF bandwidth in the UK is usually dominated by the megawatt transmissions from Rugby (GBR=16 kHz, $\mathrm{GBZ}=19.6 \mathrm{kHz})$ and Anthorn $(\mathrm{GQD}=19 \mathrm{~Hz})$. Other common VLF peaks include 16.8, 18.3, 21.4, 23.4 and $24 \mathrm{kHz}$.

In moderately resistive environments, the conventional VLF bandwidth provides penetration depths of the order of tens of metres. In principal, the VLF bandwidth can be extended to higher frequencies (i.e. towards $1 \mathrm{MHz}$ ) using a variety of civil and commercial radio sources which again have directional propagation characteristics and which exist as line spectra. The higher frequencies are intended to provide a much shallower sounding capability since penetration depths can be reduced towards $1 \mathrm{~m}$. One early system, operating at $60 \mathrm{kHz}$, is described by LaFleche and Jensen (1982). More recently the extension of VLF-R to higher frequencies has been denoted radiomagnetotellurics (RadioMT, Turberg et al., 1994; Zacher et al., 1996). The highest frequencies used in RadioMT are reported to be $240 \mathrm{kHz}$.

upper $10 \mathrm{~m}$ at $20 \mathrm{kHz}$ and the upper $2 \mathrm{~m}$ at $500 \mathrm{kHz}$.

Subsurface penetration in plane-wave electromagnetic investigations is determined by the electrical skin-depth which is a function of frequency. The requirement for multifrequency observations is a one-dimensional (1D) 'vertical-sounding' concept dating back to the original founding work on magnetotellurics (Cagniard, 1953). For a 1D resistivity assessment there is a clear requirement to obtain a sufficient density of measurements per decade of bandwidth in the sounding curve in order to adequately resolve subsurface layering. When the resistivity structure is $2 \mathrm{D}$ and $3 \mathrm{D}$, subsurface resolution issues are more complicated but clearly depend both on the spectral density content of the observations (including both high and low frequency limits) and the lateral scale and density of the measurements.

The VLF method differs from the more common DC resistivity site investigation technique in being a roving (mobile sensor) survey operation. Commercial systems offer both galvanic (contacting) and capacitive (non-contacting) electrode sensors. The non-contacting measurement of the electric field allows operation over madeground. In contrast to many methods, the techniques use vector (directional) fields to probe $2 \mathrm{D}$ and $3 \mathrm{D}$ resistivity configurations.

Increasingly detailed investigations of the near-surface are a requirement of applied geophysical investigations particularly in the environmental and hydrogeological sectors. In order to avoid misleading interpretations, the resolution attributes of single frequency data when combined with recent plane-wave regularised inversion schemes are investigated here. When single frequency VLF data are collected at a high lateral 
density (1 to $5 \mathrm{~m}$ ), the measurements can be used to infer the main elements of the subsurface resistivity distribution.

VLF-R survey data from both hydrogeological and waste-site assessments, aided by wide-band (VLF/RadioMT) synthetic modelling and inversion studies, are used to illustrate their shallow (0 to $20 \mathrm{~m}$ ) resolution capabilities in predominantly conductive environments.

\section{D ASSESSMENTS}

The limited frequency range of VLF and RadioMT data provides a problem for the assessment of the 1D vertical resistivity structure. Figure 1 shows the plane-wave response, across 4 decades of frequency, of both a two-layer and a three-layer model. Both models contain a first interface depth at $10 \mathrm{~m}$. The two layer model has a resistivity of $20 \mathrm{ohm} . \mathrm{m}$ above a half-space of $5 \mathrm{ohm} . \mathrm{m}$. The three layer model is similar but has an additional thin layer of 1 ohm.m between 10 and $11 \mathrm{~m}$. The thin layer is detectable since its conductance $(1 \mathrm{~S})$ exceeds that of the overburden $(0.5 \mathrm{~S})$.

The diffusive nature of the plane-wave response, in a 1D environment, is illustrated in the response of both models. In order to fully detect both near surface (20 ohm.m) and deeper (5 ohm.m) features of the models it is evident that measurements across a wide frequency range, of the order of the 4 decades shown, are required. The conventional VLF bandwidth (15 to $30 \mathrm{kHz}$ ), for the models used, provides a response that is intermediate between the shallow and deeper response characteristics. The extended higher frequency (RadioMT) response is likely to improve the resolution of the upper layer but full definition of the lower half-space is beyond its bandwidth. The lack of deep resolution is due to the moderate resistivity assigned to the upper layer. Limited bandwidth provides only weak vertical resolution but at the site-investigation scale it is often the departures from uniformity that are of interest.

In $2 \mathrm{D}$ and $3 \mathrm{D}$ situations, the detection of the resistivity distribution relies on the excess currents generated at resistivity contrasts (Price, 1973). The distribution of excess currents then modifies the surface fields. In order to provide the excess currents, the fields must have sufficient penetration to interact with the resistivity distribution at any particular depth and location. Figure 2 shows the decay of the horizontal E-field amplitude in uniform materials having resistivities from 1 to 500 ohm.m at frequencies of $20 \mathrm{kHz}$ (Fig. 2a) and $500 \mathrm{kHz}$ (Figure 2b). The horizontal dash line denotes one skin-depth across the set of resistivities. Investigation depths, in a 1D context, can be considered to be a factor of 1.5 times the skin-depths shown (Spies, 1989). For a moderate resistivity of $50 \mathrm{ohm} . \mathrm{m}$, investigation depths range from about $40 \mathrm{~m}$ at $20 \mathrm{kHz}$ to about $7.5 \mathrm{~m}$ at $500 \mathrm{kHz}$. When highly conductive materials (e.g. 1 ohm.m), such as leachate plumes, are encountered, penetration depths are confined to the upper $10 \mathrm{~m}$ at $20 \mathrm{kHz}$ and the upper $2 \mathrm{~m}$ at $500 \mathrm{kHz}$.

\section{D MODELLING AND INVERSION}

As discussed by Fischer et al. (1983) and Beamish (1994) in order to ensure consistency with a 2-D approach, the directional VLF data must conform to one of the 
two principal modes of 2-D induction. The assumption of infinite strike (which defines the 2-D case) provides two decoupled modes involving separate combinations of the field components. The TE-mode (or E-polarisation, electric field parallel to strike) involves surface fields of Ex, Hy and Hz. The TM-mode (or H-polarisation, magnetic field parallel to strike) involves the surface fields Hx, Ey and Ez. Due to the directional nature of VLF measurements, we require therefore that the measurements be made in, at least one, of the two principal directions. Where anomaly strikes are not known, the survey option of taking measurements from several azimuthallydistinct transmitters is suggested.

The TE-mode provides VLF-R and VLF-Z data and anomaly wavelengths are generally larger than their TM-mode counterparts. In the TM-Mode, no VLF-Z field is generated and thus combined measurements of VLF-R and VLF-Z can be used as a means of mode identification. The starting point in the modelling of VLF data are the developments in non-linear inversion which have arisen in the context of the multifrequency magnetotelluric (MT) technique. The new approaches involve regularising an otherwise 'ill-posed' problem by introducing a smooth or minimum-structure constraint. In 2-D inversion, the problem of equivalence becomes particularly acute because of the larger number of degrees of freedom within the model space. The essential point is that the minimum-structure inversion concept acknowledges this fact and allows the construction of credible (non-extreme) resistivity models.

For 2-D MT inversion, deGroot-Hedlin and Constable (1990) implemented a minimum-structure inversion which is referred to as OCCAM and is based on the finite-element forward solution of Wannamaker et al. (1987). A more rapid 2D inversion code involving a non-linear, conjugate gradient (NLCG) algorithm has recently been described by Rodi and Mackie (1999). The algorithm implements firstderivative smoothing and includes a regularisation parameter $(\tau)$ that controls the degree of model smoothness/roughness (often a trade-off with misfit). VLF studies using the former method were described by Beamish (1994). The latter method is used in the present study since it readily permits the use of a regular subsurface finitedifference grid comprising in excess of 100x100 $1 \mathrm{~m}$ cells. The use of such a high definition subsurface grid (in terms of electrical scale lengths) allows the true nature of smooth resistivity models to be displayed (i.e. resistivity boundaries imaged as spatial gradients).

The measured data should possess error bounds. An exact fit between measured and modelled data is rarely warranted. The error bound must comprise the variance associated with physical measurement but it can also encompass the degree to which a particular level of modelling (e.g. 1D, 2D or 3D) is thought to be appropriate. Given a set of $N$ observations $\left(d_{i}, i=1, N\right)$ with standard errors $\left(\sigma_{i}\right)$, the concept is to only fit the observations to within a prescribed level of misfit. When the data and errors conform to Gaussian behaviour the chi-square $\left(\chi^{2}\right)$ statistic is a natural measure of misfit :

$$
\chi^{2}=\left(\mathrm{d}_{\mathrm{i}}-\mathrm{m}_{\mathrm{i}}\right)^{2} / \sigma_{\mathrm{i}}^{2}
$$

where $m_{i}$ refers to the i'th model response. An r.m.s. measure of misfit defined as $\chi^{2} / \mathrm{N}$ with an expectation value of unity is used here. 


\section{A SYNTHETIC EXAMPLE}

In the applied use of VLF for many types of investigation, the choice of transmitter appears to be either a signal/noise issue or is not discussed at all. For resistivity mapping purposes the use of two azimuthally distinct transmitters is recommended (Beamish, 1998). The two joint data sets allow rotational invariants to be formed thus overcoming the dependence of anomaly response using single transmitter data. The choice of survey transmitter(s) is also a critical issue when subsurface resistivity information (in cross-section) is required. The initial choice(s) will govern the direction of the survey profile and the azimuth at which the orthogonal $\mathrm{E}$ and $\mathrm{H}$ field components will be recorded. For a given resistivity distribution the choice of transmitters and their directions will govern the form and resolution characteristics of the data set obtained. For the elongate, 2D anomalies principally discussed here, the main issue is the combination of transmitter azimuth and anomaly strike direction that determine the mode of the response that is measured.

A synthetic example is used to demonstrate the differences in data characteristics that are observed in the two modes. The study also allows resolution issues of the field data examples to be examined. The model study uses a typical site-investigation profile length of $100 \mathrm{~m}$. The central subsurface of the model comprises 100 (horizontal) x 50 (vertical), $1 \mathrm{~m}$ cells before expansion to satisfy boundary condition requirements.

The study model, shown in Figure 3, contains two concealed conductive (5 ohm.m) bodies located at depths of 2 and $5 \mathrm{~m}$ in host material with a resistivity of $50 \mathrm{ohm} . \mathrm{m}$. The larger and deeper conductive feature is laterally extensive and has a rotated ' $\mathrm{L}$ ' shape. An at-surface resistive feature (500 ohm.m) with a thickness of $2 \mathrm{~m}$ is also present. As will be demonstrated, the presence of at-surface resistivity contrasts has a profound influence on the characteristics of the TM-mode data. The multi-body model provides anomaly wavelengths that overlap (in the TE-mode) making simple interpretation of the observational data difficult.

In order to extend the context of single frequency VLF observations, the response of the model at a range of higher frequencies (RadioMT) has been examined. Four frequencies of $20 \mathrm{kHz}$ (VLF), $50 \mathrm{kHz}, 200 \mathrm{kHz}$ and $500 \mathrm{kHz}$ are used. Skin-depths range from $25 \mathrm{~m}$ at $20 \mathrm{kHz}$ to $5 \mathrm{~m}$ at $500 \mathrm{kHz}$ in the host background of $50 \mathrm{ohm} . \mathrm{m}$.

In Figure 3 profile measurements are across the page with body strike into the page. The TE-mode uses E-field measurements into the page while in the TM-mode the Efield would be measured across the page. Following a discussion of the data characteristics inversions of the single (VLF) frequency and multi-frequency data are performed.

When dealing with complex resistivity distributions at the site investigation scale, the behaviour of the TM-mode apparent resistivity to near-surface resistivity contrasts is an important feature. As noted in the review by Jiracek (1990), any resistivity contrast due to small-scale heterogeneities in the vicinity of the electric field measurement can give rise to a particular class of perturbation referred to as galvanic distortion or static 
shift. Such effects are observed irrespective of electrode type (e.g. contacting or noncontacting).

The phenomenon is well-known from lower frequency investigations (Magnetotelluric) but is also evident at VLF and higher frequencies when near-surface features cause large fluctuations in apparent resistivity. If the phenomenon is not understood, the data may be dismissed as 'erratic' however such data may often be of potential interest at the site investigation scale. Static shift is generated by a body of small electrical dimensions (i.e. in terms of skin-depth) in the proximity (again in terms of skin-depth) of the measurement electrodes. The measured electric field is perturbed from its 'regional' value (i.e. the value in the absence of the small-scale body) by a frequency independent shift of apparent resistivity. The phase between the electric and magnetic fields is unaffected. The scale of the perturbation depends on the resistivity contrast encountered (Beamish and Travassos, 1993).

If the problem considered is strictly two-dimensional, then static perturbation effects are confined to the TM-mode measurements. In practice, when the small-scale body is three-dimensional the perturbation will affect both modes (i.e. any VLF-R data that is collected, irrespective of orientation).

The response of the synethetic model has been calculated every $1 \mathrm{~m}$ along the surface at a VLF frequency of $20 \mathrm{kHz}$ and additional RadioMT frequencies of 50, 200 and $500 \mathrm{kHz}$. The VLF-R response in the TE- and TM-modes is shown in Figures 4 and 5 respectively. In the TE-mode (Fig. 4), the at-surface resistive body (40-50 m) produces a large amplitude perturbation in amplitude (apparent resistivity) but is far less conspicuous in the phase response. The anomaly wavelengths decrease with increasing frequency allowing better lateral definition of the location of the bodies. At the lowest (VLF) frequency the observational baseline is insufficient for the response to return to its half-space values of $50 \mathrm{ohm} . \mathrm{m}$ (apparent resistivity) and 45 degrees (phase). The electrical scale of the left-most conductive body $(20-30 \mathrm{~m})$ produces a phase inversion between low (20 and $50 \mathrm{kHz})$ and high $(200$ and $500 \mathrm{kHz})$ frequencies.

In the TM-mode (Fig. 5), the amplitude response is dominated by the largely galvanic response of the at-surface resistive body. The asymmetric behaviour of the response is due to the combined effects of the multiple bodies. When the wavenumber behaviour of the TE- and TM-mode response data (to all three bodies) is compared it can be seen that the TM-mode response consistently provides the highest lateral definition (smallest anomaly wavelengths).

\section{Data inversion}

The response characteristics of both modes contain diagnostic information on the subsurface resistivity distribution. The degree of reliable information is examined by inverting each mode separately using first the VLF single frequency data and then the RadioMT multi frequency data. The inversions of the synthetic data use apparent resistivity and phase data sampled at $1 \mathrm{~m}$ intervals. Nominal $2 \%$ errors have been assigned to the data and no random errors have been introduced. The analysis undertaken therefore represents the best possible resolution case. An initial half-space of $100 \mathrm{ohm} . \mathrm{m}$ was used to initiate the inversions. Using the assigned error limits, an 
rms misfit of unity is achieved by both inversions. Since the data are ideal, all features of the data (Figures 4 and 5) can be accurately reproduced.

The TE- and TM-mode inversion results are shown in Figures 6 and 7 respectively. The single frequency (20 kHz, VLF) inversion result is shown above the result obtained using 4 frequencies in each case. The results are contoured using the logarithm of resistivity so that the target values are 0.7 (conductive bodies of 5 ohm.m), 2.7 (resistive body of $500 \mathrm{ohm} . \mathrm{m}$ ) and 1.7 (host of $50 \mathrm{ohm} . \mathrm{m}$ ).

The outline of the original model is shown by the heavy broken lines. Inversion models with smooth constraints cannot recover discontinuous resistivity distributions; they are imaged by gradients.

In the TE-mode single frequency result (Fig. 6a) the least well-resolved feature (both laterally and vertically) is the at-surface resistive zone (40 to $50 \mathrm{~m})$. The larger and deeper conductive zone is the better resolved of the two concealed zones. The minimum resistivity values returned by the inversion appear to be located towards the 'centre-of-gravity' of the L-shaped body. The model returned using 4 frequencies of the TE-mode (Figure 6b) clearly possesses higher resolution (much tighter spatial gradients) than the single frequency case. All three features are well resolved both laterally and vertically in the attitudes and gradients of the inversion result. The conductive zones are modelled at the correct value in the central portions each feature.

In the TM-mode single frequency result (Fig. 7a) the least well-resolved feature is probably the shape and depth of the deeper conductive zone (50 to $80 \mathrm{~m}$ ). The lateral extent of all 3 features is well-resolved. The single frequency TM mode produces a very well defined images of the upper-most conductive and the at-surface resistive features. The TM-mode model returned using 4 frequencies (Figure $7 \mathrm{~b}$ ) possesses the highest resolution characteristics of all the inversions considered.

General resolution features of both modes include the fact that the upper surfaces of concealed zones are better resolved than their lower surfaces (see also Beamish, 1994). Resolution of detailed subsurface features such as that examplified by the rotated ' $L$ ' shaped body is not possible using regularised (smooth model) inversion schemes.

\section{A HYDROGEOLOGICAL FIELD EXAMPLE}

An example of VLF-R and VLF-Z data collected across a $200 \mathrm{~m}$ profile in the vicinity of a hydrogeological test site (monitoring boreholes and additional shallow geophysics) is used to illustrate: (i) the accuracy of field measurements, (ii) the importance of mode identification and (iii) small amplitude static effects.

The geological strata (superficial clays on chalk) at the site is considered to be highly uniform. Standard Schlumberger resistivity soundings along the location of the VLF traverse indicated cover sand of resistivity $200 \mathrm{ohm} . \mathrm{m}$ (0 to $1.3 \mathrm{~m}$ ), clay till of resistivity 27 to 32 ohm.m (1.3 m to between 11 and $15 \mathrm{~m}$ ) overlying chalk with a resistivity of $76 \mathrm{ohm} . \mathrm{m}$. The VLF measurements were made with a Scintrex IGS-2 system employing $5 \mathrm{~m}$ dipoles and capacitive electrodes. Separations were $5 \mathrm{~m}$ making the VLF-R measurements contiguous along the direction of the profile. The 
transmitter used was the $16 \mathrm{kHz}$ signal (Rugby, GBR). Since the site was considered laterally homogeneous, no predefined idea of mode orientation could be established and the survey azimuth and E-field orientation was based on the signal/noise of the VLF transmitter.

The real and imaginary components of the VLF-Z response are shown in Figure 8 with values being expressed as percentage. The uniformity of the response across the $200 \mathrm{~m}$ profile is such that a very detailed vertical scale of $+/-4 \%$ has been used. At this scale, the instrument noise level of $1 \%$ in both real and imaginary components can be observed. Although the real component shows a consistent negative offset of 1 to $2 \%$, the majority of the imaginary component lies very close to zero. Overall the response measured is as close to a VLF-Z zero response as can be observed over profile baselines of this length.

If only VLF-Z data had been obtained, the results might be used to provide an interpretation in terms of an entirely horizontally uniform subsurface resistivity distribution. This is clearly not the case when the coincident VLF-R measurements are taken into account. Figure 9 shows the behaviour of the VLF-R response (shown as symbols) along the profile. A frame box has been used to highlight the behaviour observed across the first $140 \mathrm{~m}$ of the profile; apparent resistivities are largely confined to 25 to $30 \mathrm{ohm} . \mathrm{m}$ and phase values to 40 to 45 degrees. The instrument resolution level is $1 \mathrm{ohm} . \mathrm{m}$ and 1 degree. Within the frame box apparent resistivities tend to oscillate at the measurement separation scale of $5 \mathrm{~m}$ while the phase values are laterally far more consistent. The behaviour is not instrumental or measurement noise; it is an example of small-scale near-surface static effects that can be observed on many VLF-R data sets when they are examined in detail.

Beyond $140 \mathrm{~m}$, a clear longer wavelength anomalous response is observed that is not 'complete' by the end of the observational profile at $200 \mathrm{~m}$. In view of the absence of any VLF-Z response, the response must be interpreted as a strictly TM-mode response to a resistivity gradient. It is worth noting that the VLF data contain virtually no information on the vertical resistivity profile at the site, being influenced largely by the resistivities of the clay sequence (27 to $32 \mathrm{ohm} . \mathrm{m}$ ).

\section{Data inversion}

The VLF-R data have been inverted using the NLCG method. The subsurface model comprises a $5 \mathrm{~m}$ (lateral) by $1 \mathrm{~m}$ (vertical) grid across the central region. The inversions were initiated using a half-space of $25 \mathrm{ohm} . \mathrm{m}$. As with the synthetic data, arbitrary error bounds of $2 \%$ were assigned for the analysis of misfit. With these error assignments an rms misfit of $1.5 \%$ was achieved by the inversion. The observed data (symbols) are compared with the model response (continuous solid line) to the data in Figure 9. It can be seen that all the high wavenumber components of the apparent resistivity data are well modelled. The greatest level of misfit occurs at the maximum phase excursion.

The resistivity model obtained is shown, using a linear resistivity scale, in Figure 10. It can be seen that the major uniform resistivity value returned in the model is in the range 25 to 35 ohm.m in keeping with the DC resistivity survey values for the clay sequence of 27 to 32 ohm.m. The longer wavelength anomaly appears to be 
generated by a more resistive feature (55 to $60 \mathrm{ohm} . \mathrm{m}$ ) within the clay sequence centred on $180 \mathrm{~m}$. The clay sequence (Lowestoft till) can be subdivided into oxidised and unoxidised units with the latter showing a large (4 order of magnitude) decrease in hydraulic conductivity. It is likely that resistive feature represents an isolated zone of tighter, unoxidised clay.

\section{A WASTE-SITE FIELD EXAMPLE}

The next single-frequency field example comes from an assessment of a site which has been used for the disposal of industrial wastes. The data were obtained across a former quarry in sandstone which was used for a wide-variety of industrial wastes with original and by-products being lime slurries, brines, metal waste, DNAPL's and acidic leachates. The measurements were made with a Scintrex IGS-2 system employing $5 \mathrm{~m}$ dipoles and used the Rugby VLF transmitter (GBR, $16 \mathrm{kHz}$ ).

The profile comprises 83 observations made in the TM-mode with a station sampling of $1 \mathrm{~m}$. The TM-mode is defined with the E-field measurements made perpendicular to the former quarry edge. The $1 \mathrm{~m}$ data interval represents oversampling since the dipole length remains fixed at $5 \mathrm{~m}$. The discontinuous nature of the TM-mode response and the likely presence of debris noise suggests that oversampling may be appropriate in the absence of an ability to use dipole lengths of $1 \mathrm{~m}$. The data obtained are shown by the symbols in Figure 11. In this example, apparent resistivities reach a lower instrument level of $1 \mathrm{ohm} . \mathrm{m}$ and phase values reach a value of 90 degrees.

\section{Data inversion}

The VLF-R data have been inverted using the NLCG method and assuming the data conform to the TM-mode. The subsurface model comprises a $1 \mathrm{~m}$ (lateral) by $1 \mathrm{~m}$ (vertical) grid across the central region of $100 \mathrm{~m}$. The inversions were initiated using a half-space of $10 \mathrm{ohm} . \mathrm{m}$. As with the synthetic data, arbitrary error bounds of $2 \%$ were assigned for the analysis of misfit.

Figure 12 shows the results of two inversions. In Figure 12a, a smoothing parameter of $\tau=30$ was used and the rms misfit achieved was $5 \%$. The fit of the model to the data is shown in Figure 11 by the continuous solid line. It can be seen that the misfit largely stems from the observed phase excursions to high values. The resulting inversion model (Figure 11a) contains largely moderate wavenumber components in the resistivity distribution.

It is possible to reduce the misfit by decreasing the degree of smoothing in the inversion model. Figure 12b shows the result of decreasing the smoothing parameter $(\tau=1)$ which allows the rms misfit to decrease from $5 \%$ to $3.6 \%$. The fit of this second model to the data is shown in Figure 11 by the broken line. It is evident that only a marginal improvement in fit is achieved. The resulting model however, while retaining the moderate wavenumber features of the previous model, amplifies two high wavenumber components of the resistivity distribution which are associated with the maximum phase excursions. It is likely that only the resistivity distribution shown in Figure 11a is warranted by the fit to the data. The high wavenumber components 
introduced into the most conductive zones are likely to be 3D effects which cannot be effectively modelled.

The result of Figure 12a represents the minimum structural model that is consistent with the observations. Discontinuous features, if they exist, are represented by the changes in gradients. A large wavenumber trend of low resistivity values $(<10$ ohm.m) suggests a dip of conducting infill from left to right across the western margin of the profile. Several metres of resistive infill occur between 50 and $100 \mathrm{~m}$. Two highly conducting ( $<1 \mathrm{ohm} . \mathrm{m})$ zones are detected between depths of 5 and $10 \mathrm{~m}$, centred on profile locations of 70 and $90 \mathrm{~m}$. The zones are laterally compact and may be less than $5 \mathrm{~m}$ in width. The base of conducting infill of the quarry (the original quarry floor is thought to be at a depth of $25 \mathrm{~m}$ ) cannot be resolved due to rapid attenuation in the conductive environment.

\section{CONCLUSIONS}

VLF data can be obtained rapidly, accurately and at low survey cost over both made and unmade ground at the site investigation scale. Often large quantities of such data are acquired but the information contained is not exploited in a quantitative manner. The study has demonstrated that when single frequency VLF data are collected at a high lateral density ( 1 to $5 \mathrm{~m}$ ), the measurements can be used to infer the main elements of the subsurface resistivity distribution. The tools required are the regularised, smooth model inversion schemes that have been developed for multifrequency, magnetotelluric data sets. The use of extended frequency (RadioMT) data, when available, will invariably add to the resolution capabilities of the method as long as signal/noise remains high. The additional constraints essentially provide only second-order improvements in the detection of target structure boundaries. It appears that the spatial gradients generated at the lowest (VLF) frequency contain a high degree of information on the configuration of the subsurface resistivity distribution. A critical issue in VLF survey planning and transmitter selection is the choice of anticipated structural strike and thus the mode of the profile data obtained. As the hydrogeological example shows, the joint acquisition of VLF-Z and VLF-R data can be used as an aid to mode identification.

\section{ACKNOWLEDGEMENTS}

My thanks go to the people who have contributed so much to improve the capabilities of electromagnetic geophysics (and my understanding of survey data) by developing sound modelling and inversion strategies: Phil Wannamaker, Catherine deGrootHedlin, Steve Constable and Randy Mackie. The report is published with the approval of the Director, British Geological Survey, a component body of the Natural Environment Research Council. 


\section{REFERENCES}

Beamish, D., 1994. Two-dimensional, regularised inversion of VLF data. Journal of Applied Geophysics, 32: 357-374.

Beamish, D., 1998. Three-dimensional modelling of VLF data. Journal of Applied Geophysics, 39: 63-76.

Beamish, D. and Travassos, J.M., 1993. A study of magnetotelluric static distortion in the context of intrusive volcanism. Geophys. Prospect., 41, 61-82.

Benson, A.K. Payne, K.L. and Stubben., 1997. Mapping groundwater contamination using dc resistivity and VLF geophysical methods - a case study. Geophysics, 62, 8086.

Cagniard, L., 1953. Basic theory of the magneto-telluric method of geophysical prospecting. Geophysics, 18: 605-635.

Constable, S.C., Parker, R.L. and Constable, C.G., 1987. Occam's inversion : a practical algorithm for generating smooth models from EM sounding data. Geophysics, 92: 289-300.

deGroot-Hedlin, C.M. and Constable, S.C., 1990. Occam's inversion to generate smooth, two-dimensional models from magnetotelluric data. Geophysics, 55: 16131624.

Fischer, G., Le Quang, B.V. and Muller, I., 1983. VLF ground surveys, a powerful tool for the study of shallow two-dimensional structures. Geophys. Prosp., 31: 977991.

Guerin, R., Tabbagh, A., Benderitter, Y. and Andrieux, P., 1994. Invariants for correcting field polarisation effects in MT-VLF resistivity mapping. Journal of Applied Geophysics, 32: 375-383.

Jiracek, G,R., 1990. Near-surface and topographic distortions in electromagnetic induction. Surv. In Geophys., 11, 163-203.

Kaikkonen, P. and Sharma, S.P., 1998. 2-D nonlinear joint inversion of VLF and VLF-R data using simulated annealing. Journal of Applied Geophysics, 39: 155-176.

Keller, G.V. and Frischknecht, F.C., 1966. Electrical Methods in Geophysical Prospecting. Pergamon Press.

LaFleche, P.T. and Jensen, O.G., 1982. Wave impedance measurements at $60 \mathrm{kHz}$. In : L.S. Collett and O.G. Jenson (Editors), Geophysical Applications of Surface Wave Impedance Measurements, Geological Survey of Canada, Paper 81-15, pp. 67-78.

McNeill, J.D. and Labson, V.F., 1991. Geological mapping using VLF radio fields. In: Nabighian, M. (Editor), Electromagnetic Methods in Applied Geophysics, Part B: Application. SEG, Tulsa, pp. 521-640. 
McNew, E.R. and Arav, S., 1995. Surface geophysical surveys of the freshwatersaltwater interface in a coastal area of Long Island, New York. Groundwater, 33: 615626.

Price, A.T., 1973. The theory of geomagnetic induction. Phys. Earth Planet. Int., 7: 227-233.

Rodi, W. and Mackie, R.L., 1999. Nonlinear conjugate gradients algorithm for 2-D magnetotelluric inversion, Geophysics, submitted.

Spies, B.R., 1989. Depth of investigation in electromagnetic sounding methods. Geophysics, 54: 872-888.

Tabbagh, A., Benderitter, Y., Andrieux, P., Decriaud, J.P. and Guerin, R., 1991. VLF resistivity mapping and verticalization of the electric field. Geophys. Prosp., 39: 10831097.

Turberg, P., Muller, I. And Flury, F., 1994. Hydrogeological investigations of porous environments by radiomagnetotelluric-resistivity. Journal of Applied Geophysics, 31: 133-143.

Wannamaker, P.E., Stodt, J.A. and Rijo, L., 1987. A stable finite element solution for two-dimensional magnetotelluric modelling. Geophys. J. R. astr. Soc., 88: 277-296.

Zacher, G., Tezkan, B., Neubauer, F.M., Hordt, A. And Muller, I., 1996. Radiomagnetotellurics: a powerful tool for waste-site exploration. European J. Environ. And Engineering Geophysics, 1: 139-159. 

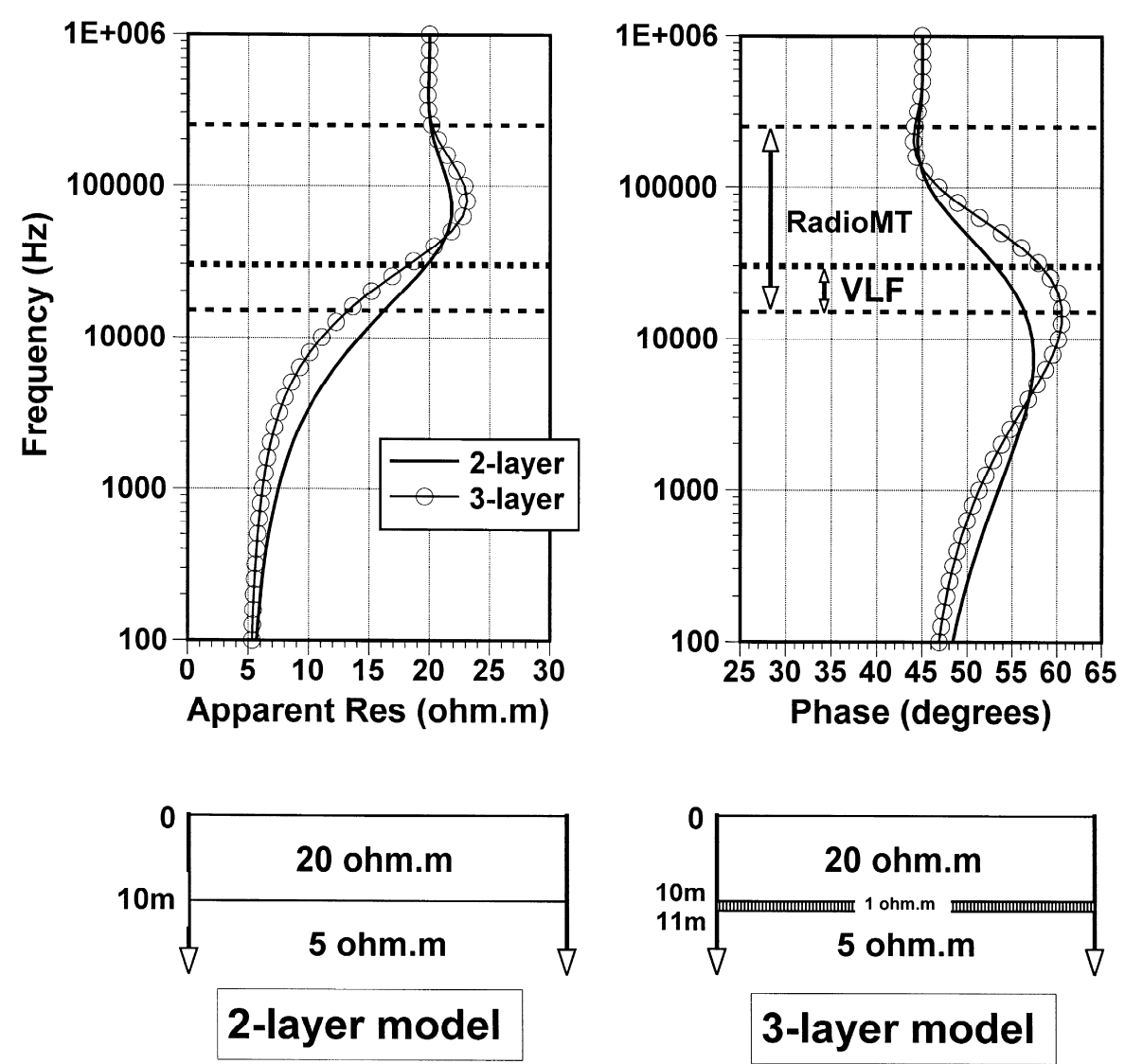

Fig. 1. Plane-wave response of two $1 \mathrm{D}$ resistivity models. Two-layer model comprises a 20 ohm.m, 10-m-thick layer above a half-space of ohm.m (solid line). The three-layer model has an additional layer of $1 \mathrm{ohm} . \mathrm{m}$ between depths of 10 and $11 \mathrm{~m}$ (line with symbols). 


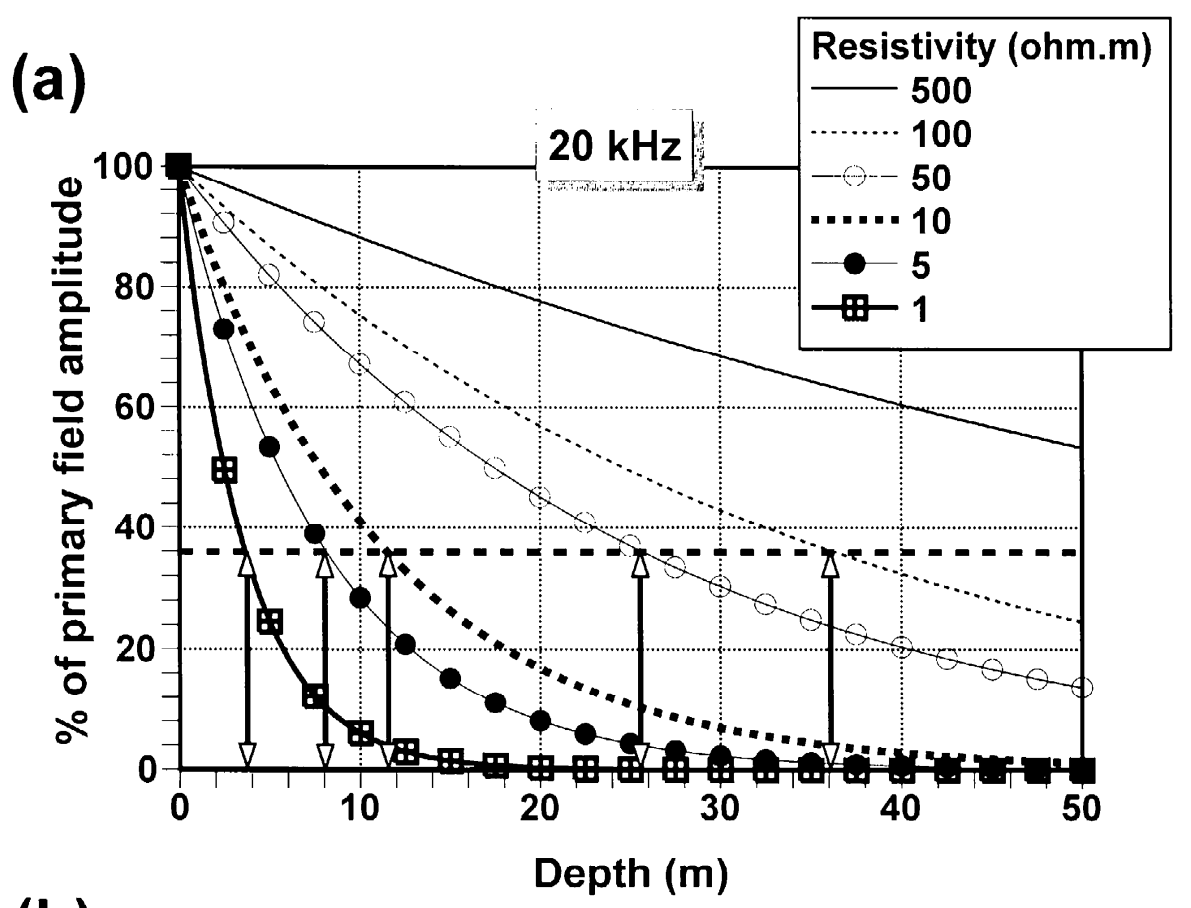

(b)

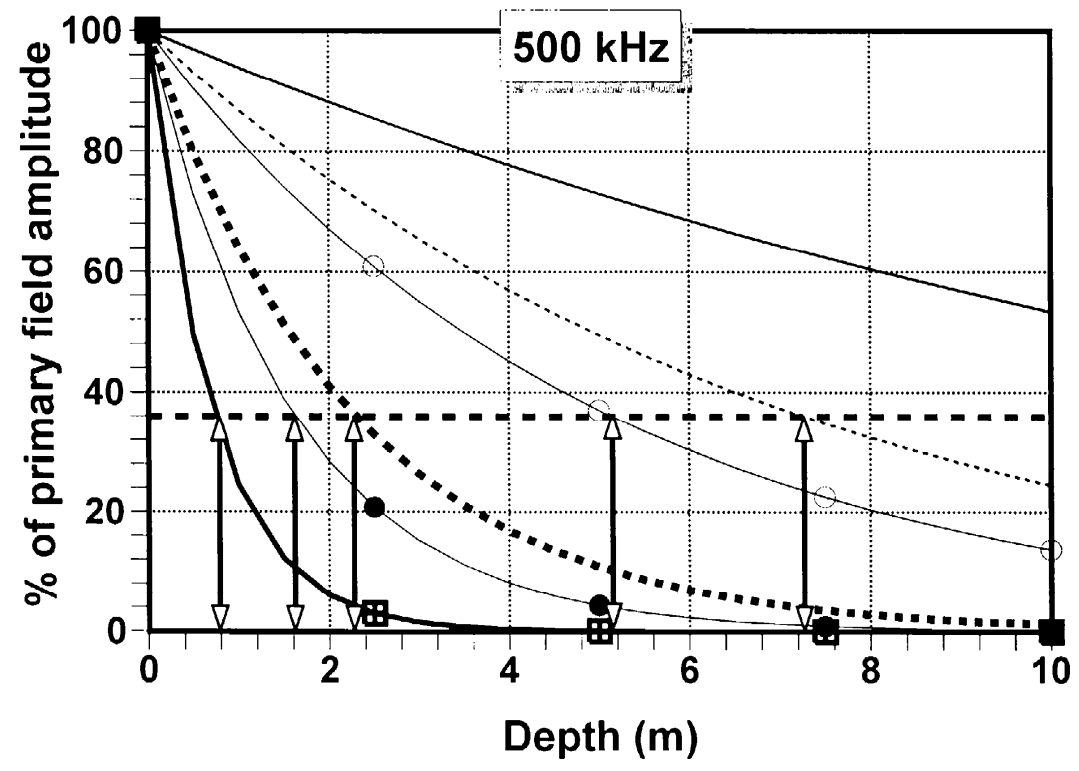

Fig. 2. Attenuation of electric field at frequencies of 20 and $500 \mathrm{kHz}$ within uniform materials having resistivities from 1 to $500 \mathrm{oh} \mathrm{m}$. $\mathrm{m}$. The horizontal dash line indicates 1 skin-depth. 


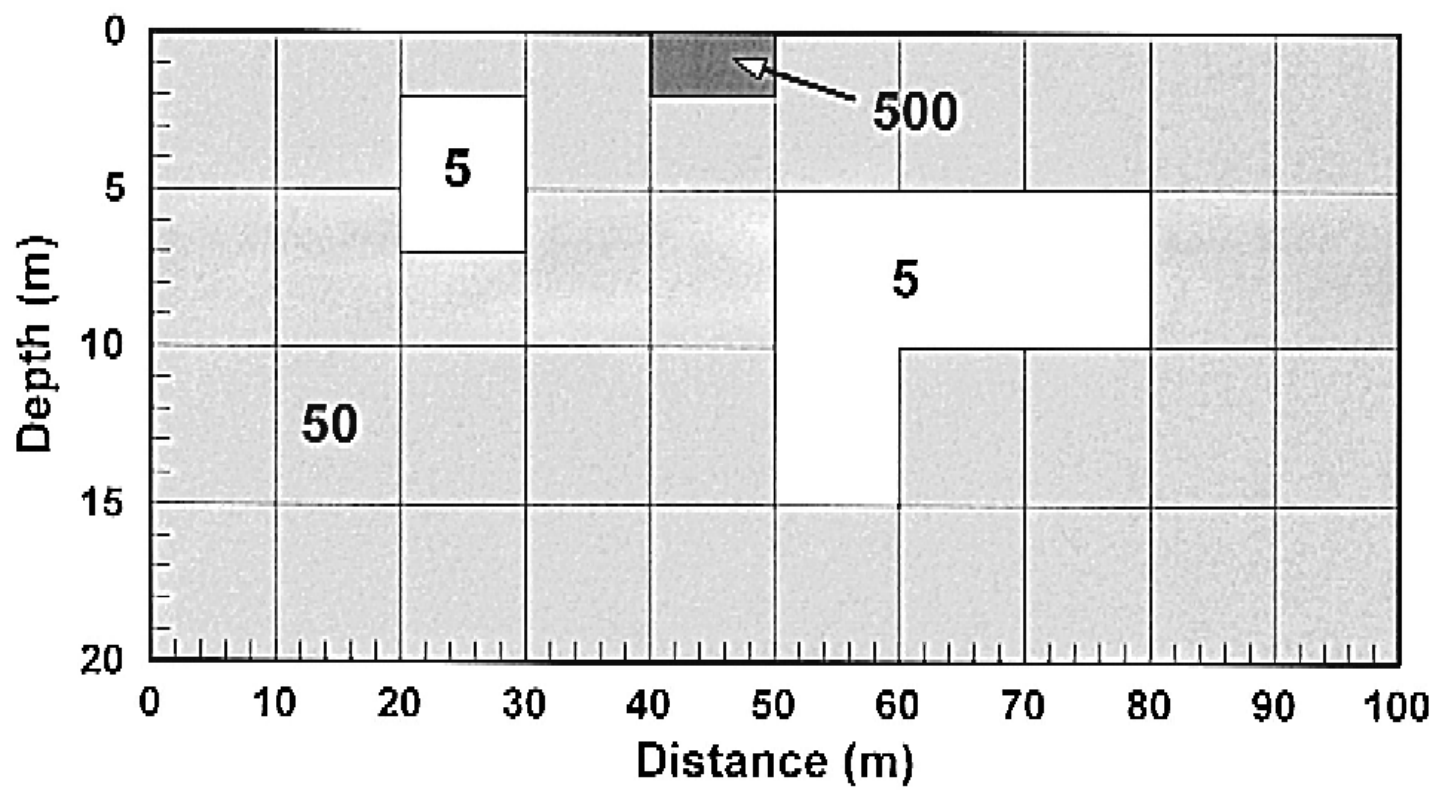

Fig. 3. 2D, three-body synthetic model. Resistivity values shown in ohm.m. 

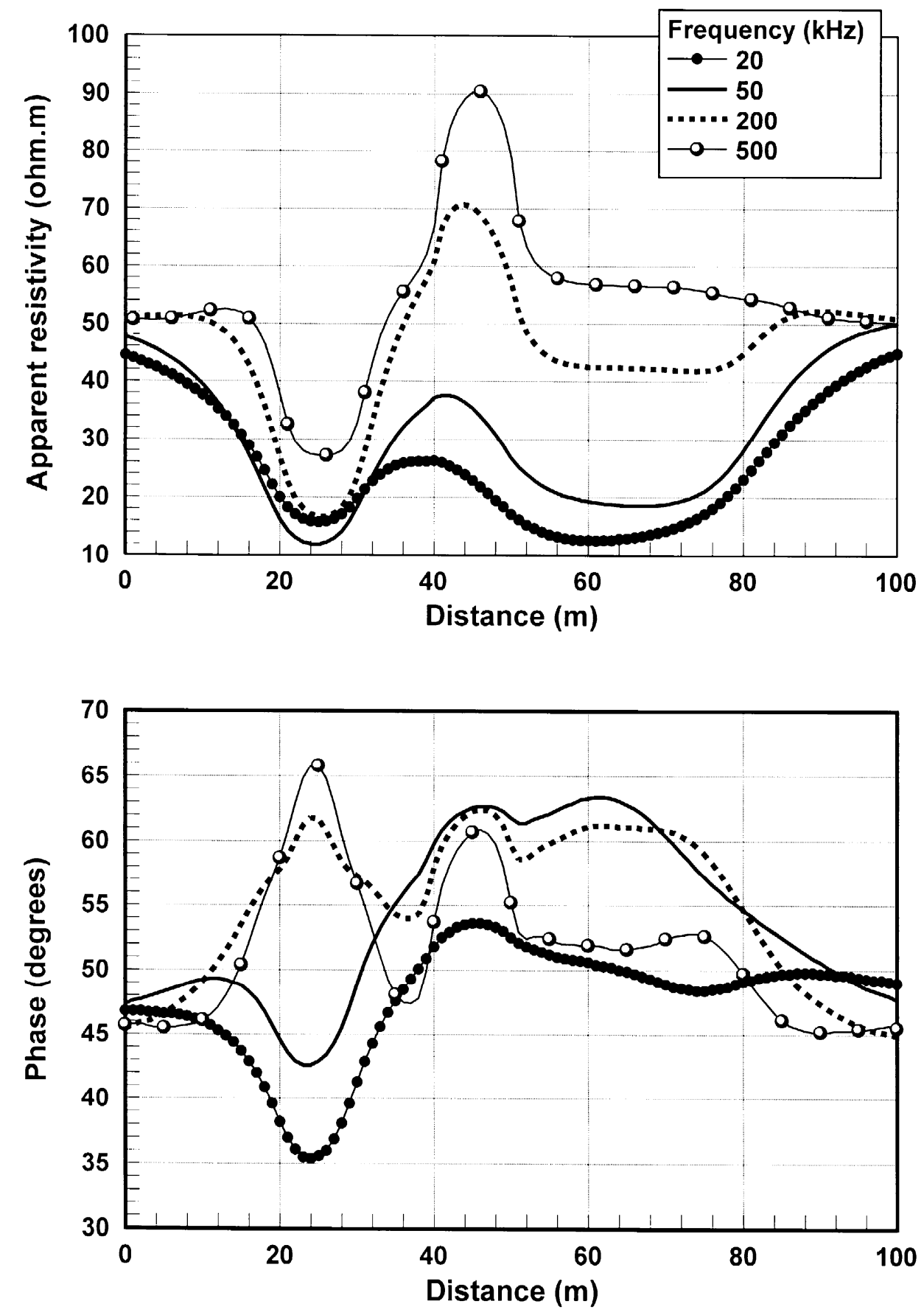

Fig. 4. Apparent resistivity and phase data calculated for the E-polarisation mode using the synthetic model of Fig. 3. The results for four frequencies are shown. 

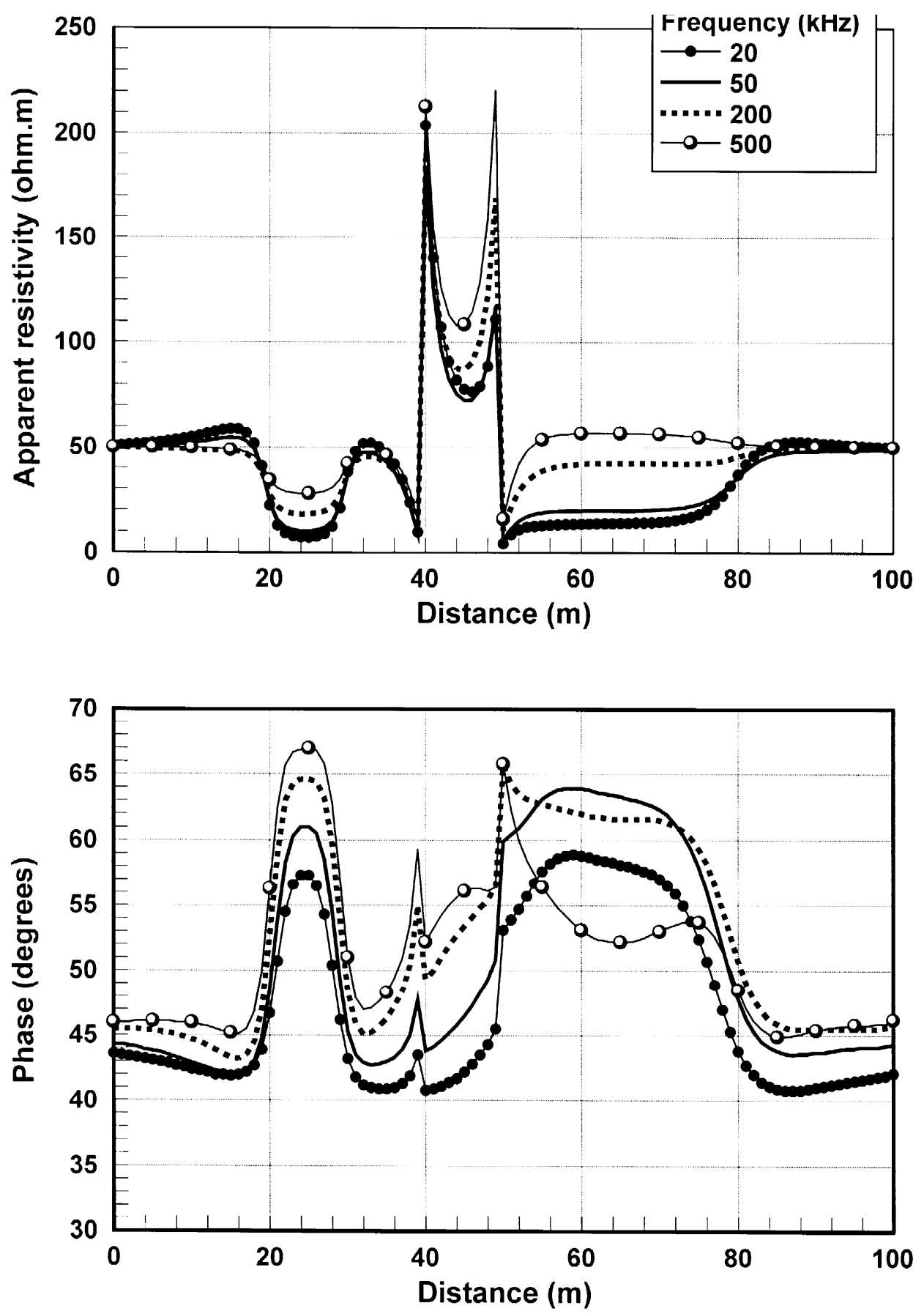

Fig. 5. Apparent resistivity and phase data calculated for the $H$-polarisation mode using the synthetic model of Fig. 3. The results for four frequencies are shown. 
a) TE, 1 Frequency

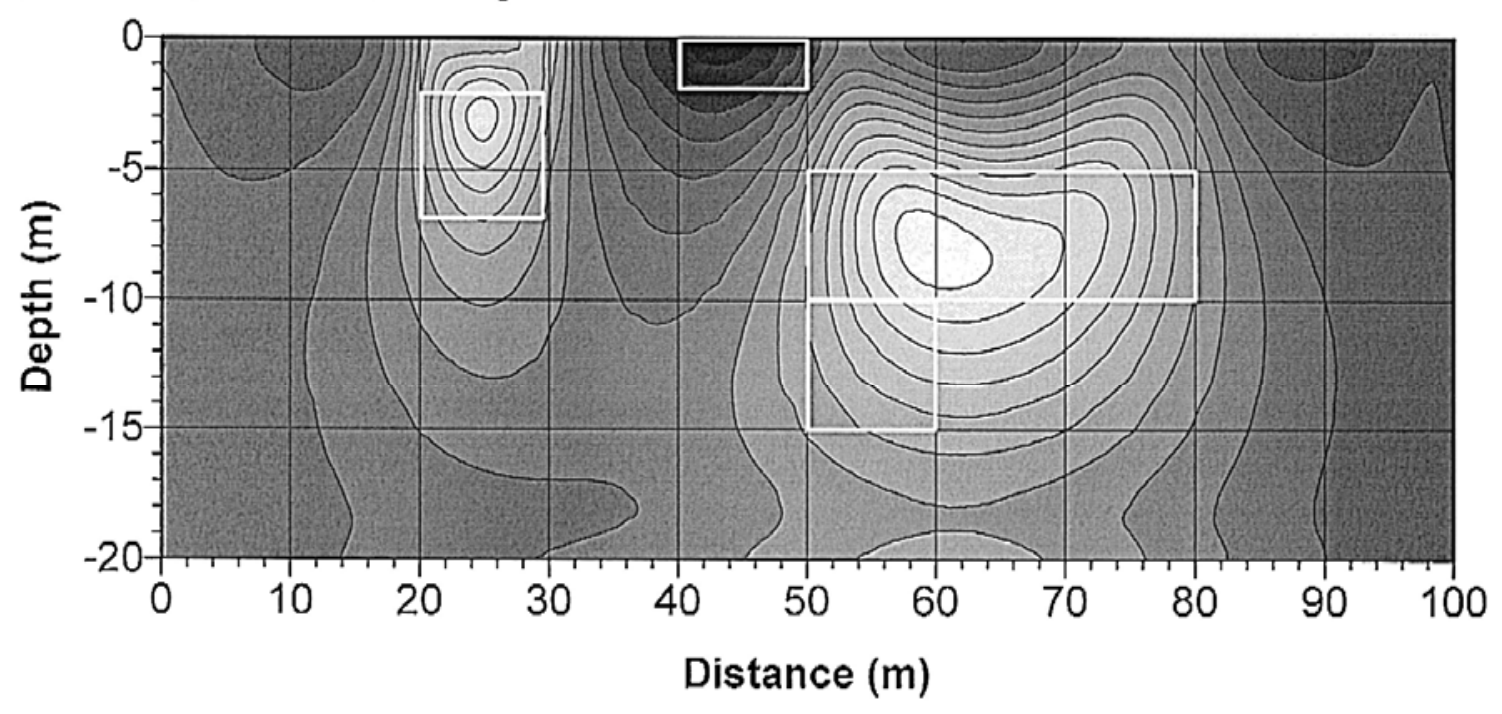

b) TE, 4 Frequencies
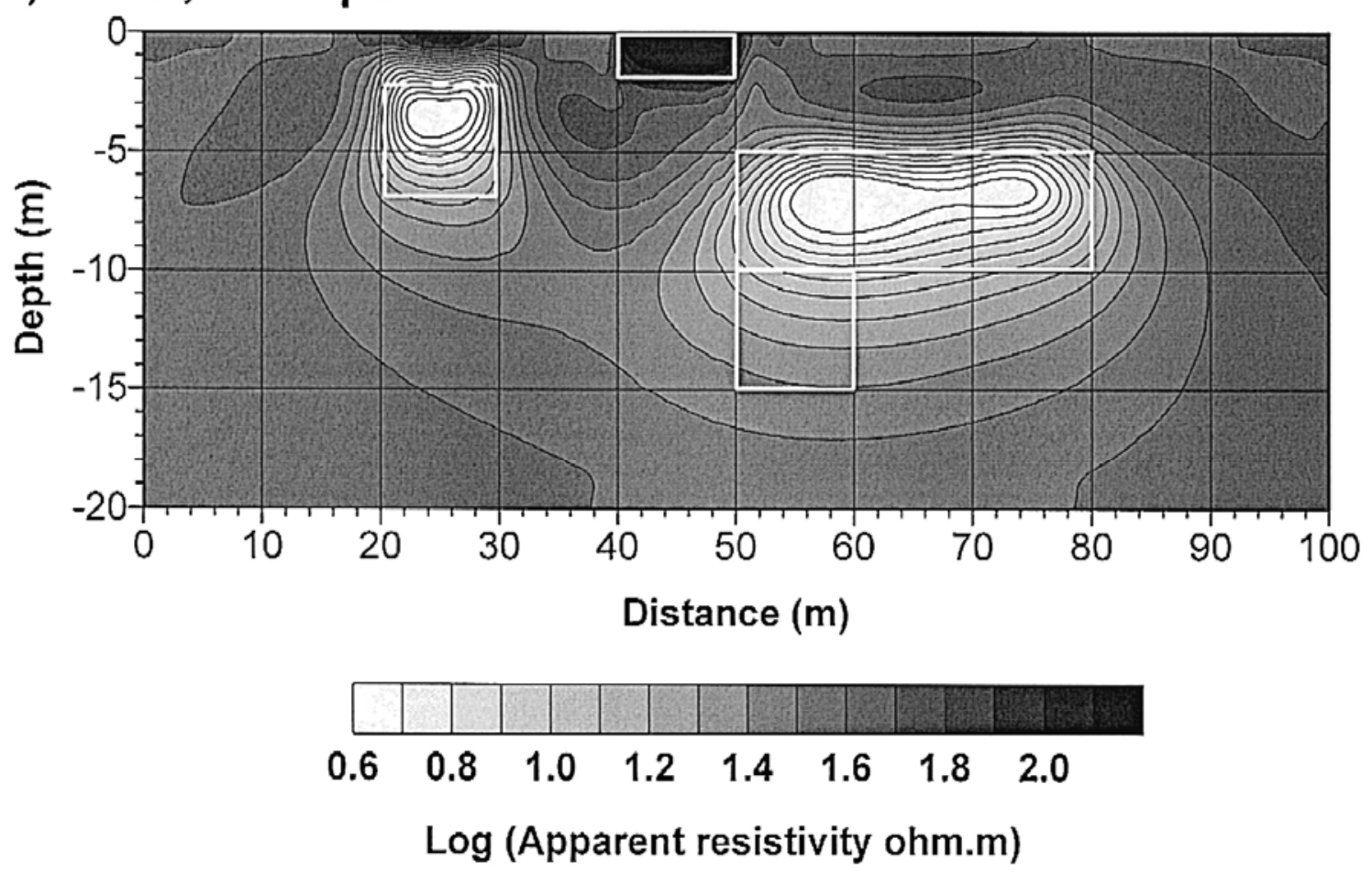

Fig. 6. Minimum structure resistivity models obtained by inverting the E-polarisation mode synthetic model data. (a) Single-frequency of $20 \mathrm{kHz}$ result. (b) Four-frequency 20, 50, 200 and $500 \mathrm{kHz}$ result. The rms misfit of both models is unity assuming $2 \%$ data errors. Original model shown by white lines. Logarithm of resistivity is contoured. Vertical exaggeration=2. 
a) TM, 1 Frequency

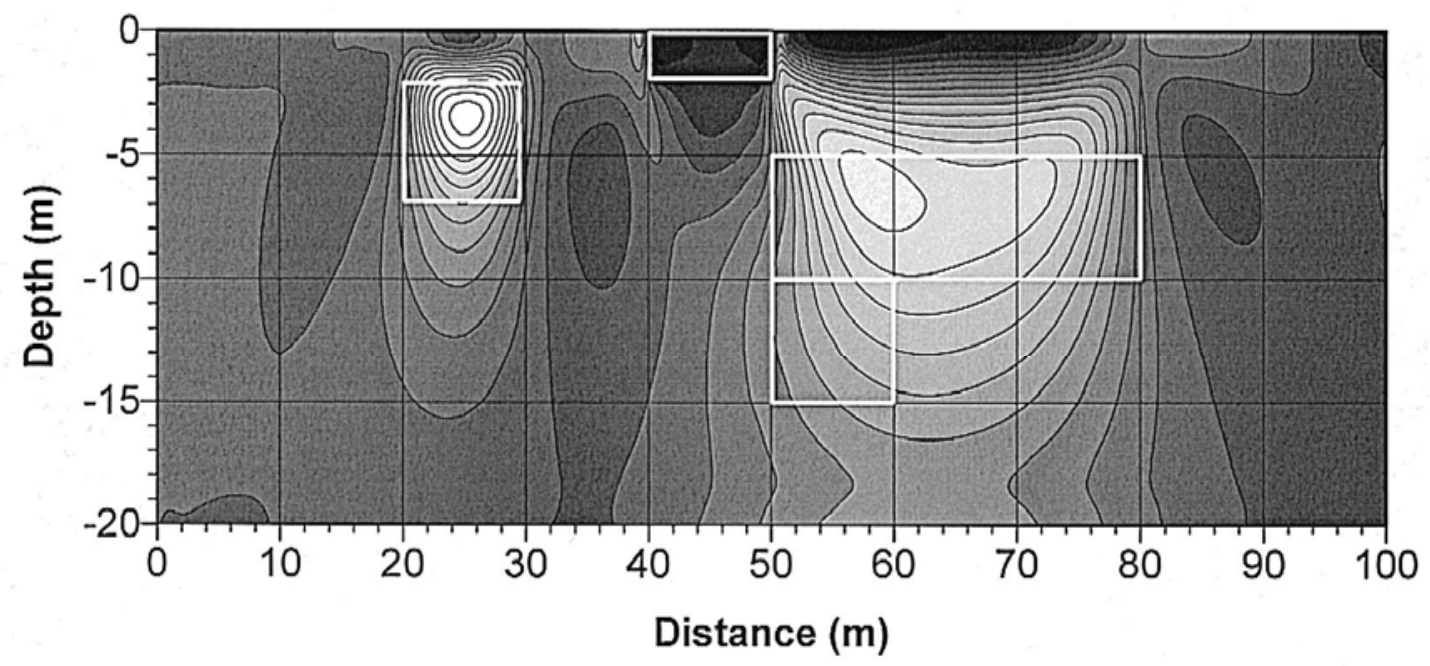

b) TM, 4 Frequencies
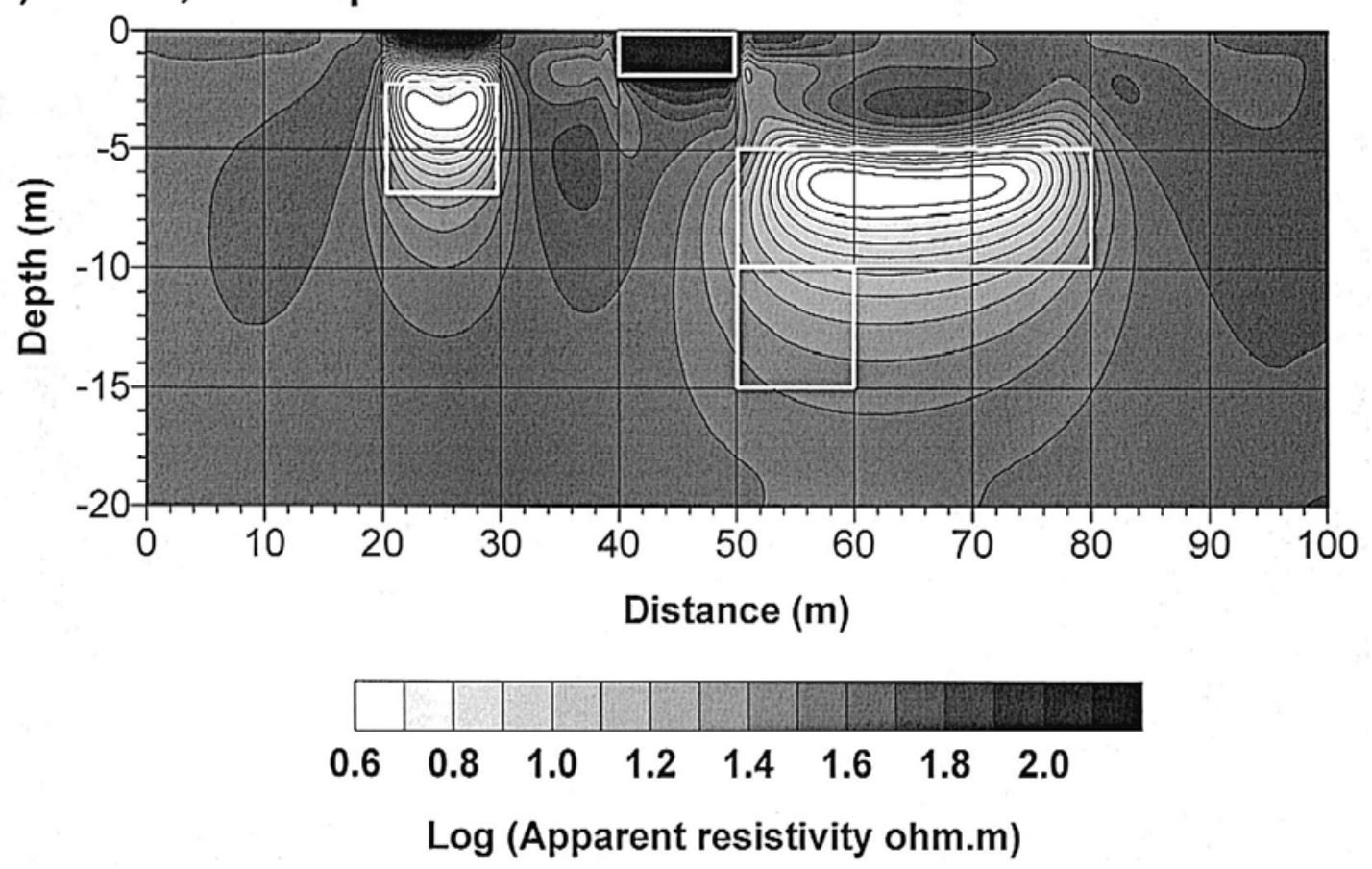

Fig. 7. Minimum structure resistivity models obtained by inverting the $H$-polarisation mode synthetic model data. (a) Single-frequency $20 \mathrm{kHz}$ result. (b) Four-frequency 20, 50, 200 and $500 \mathrm{kHz}$ result. The rms misfit of both models is unity assuming $2 \%$ data errors. Original model shown by white lines. Logarithm of resistivity is contoured. Vertical exaggeration=2. 

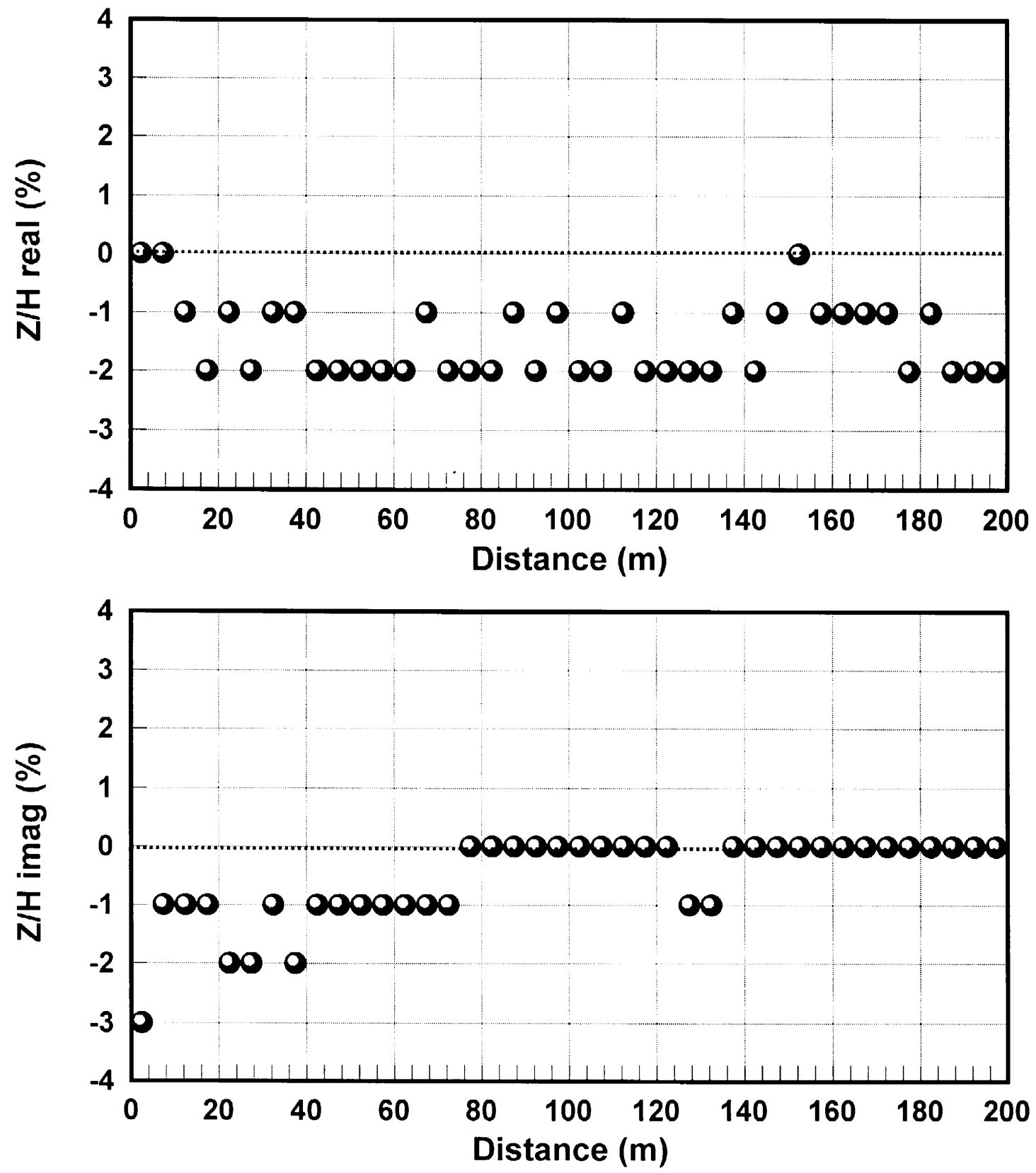

Fig. 8. Hydrogeological field example: Real and imaginary components of VLF-Z, $16 \mathrm{kHz}$ measurements obtained along a 200-m profile. Measurement separation is $5 \mathrm{~m}$. 

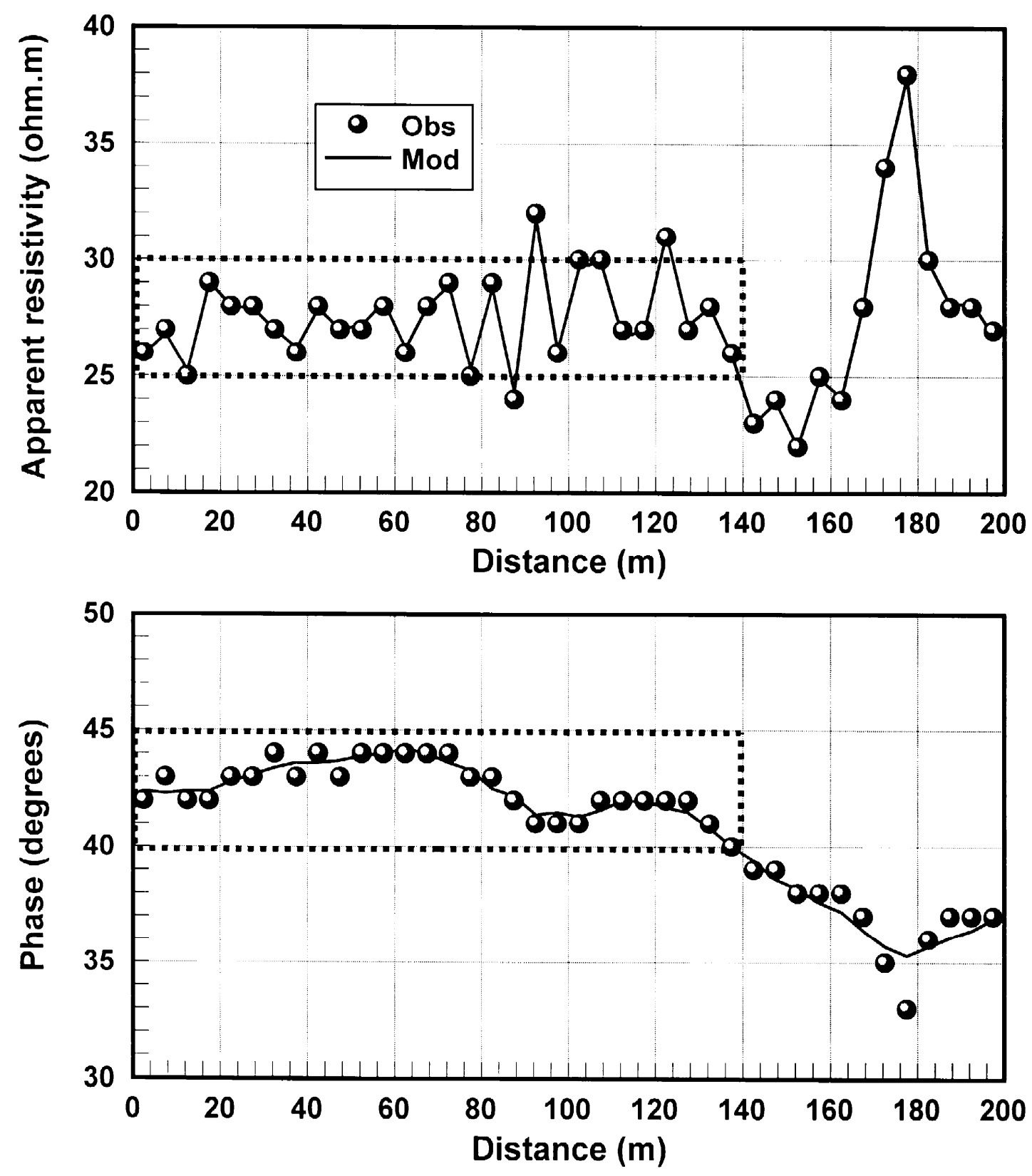

Fig. 9. Hydrogeological field example: VLF-R, $16 \mathrm{kHz}$ measurements (symbols) obtained along a 200-m profile. Measurement separation is $5 \mathrm{~m}$. The field data are compared with the response of an inversion model (continuous line). The rms misfit between data and model is $1.5 \%$ assuming $2 \%$ data errors. 

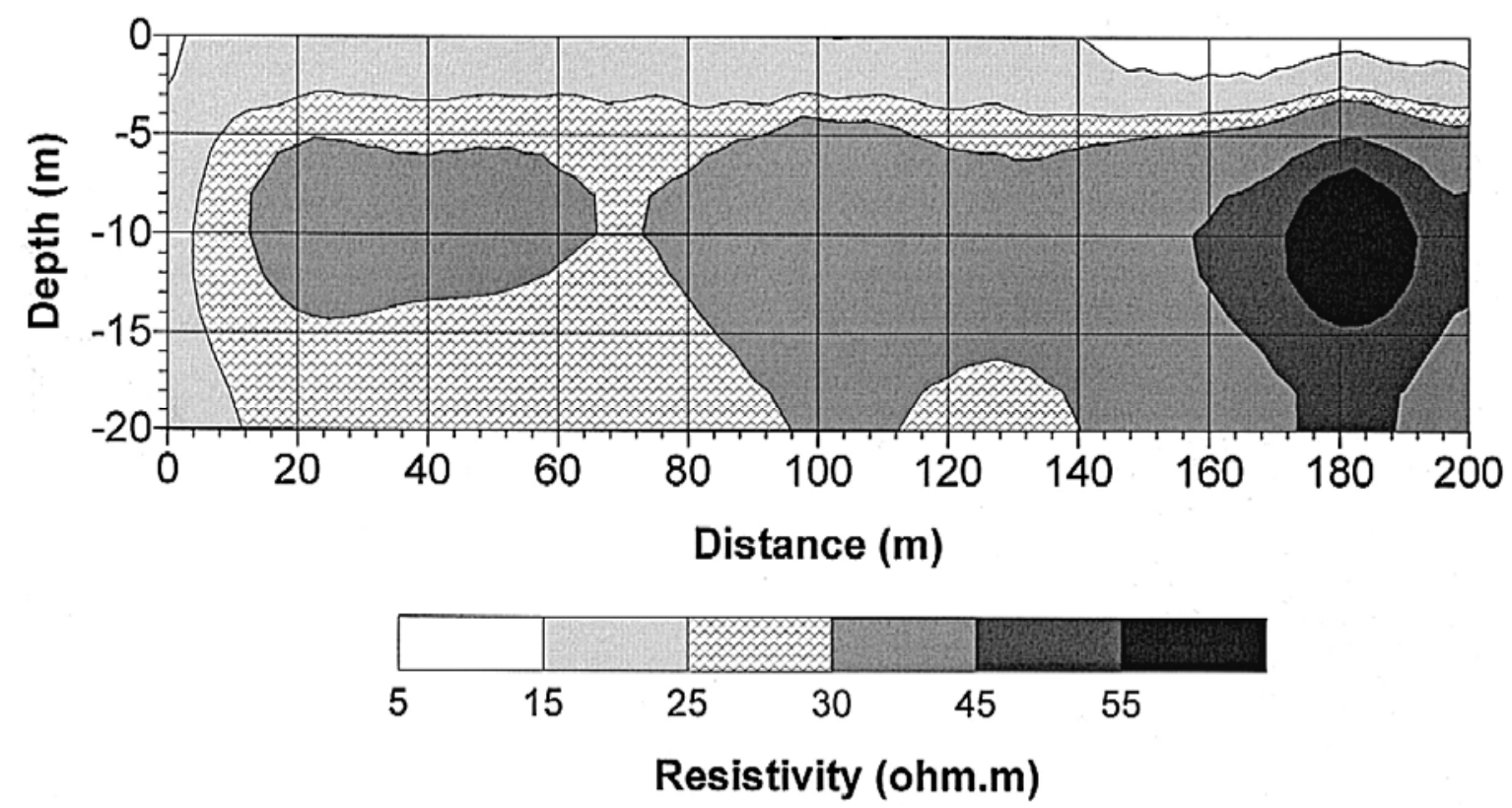

Fig. 10. Hydrogeological field example: Minimum-structure resistivity model obtained by inverting the VLF- $R, H$-polarisation mode data shown in Fig. 9. The rms misfit of the model is $1.5 \%$ assuming $2 \%$ data errors. Cross-section is contoured using linear resistivity. Vertical exaggeration $=3$. 

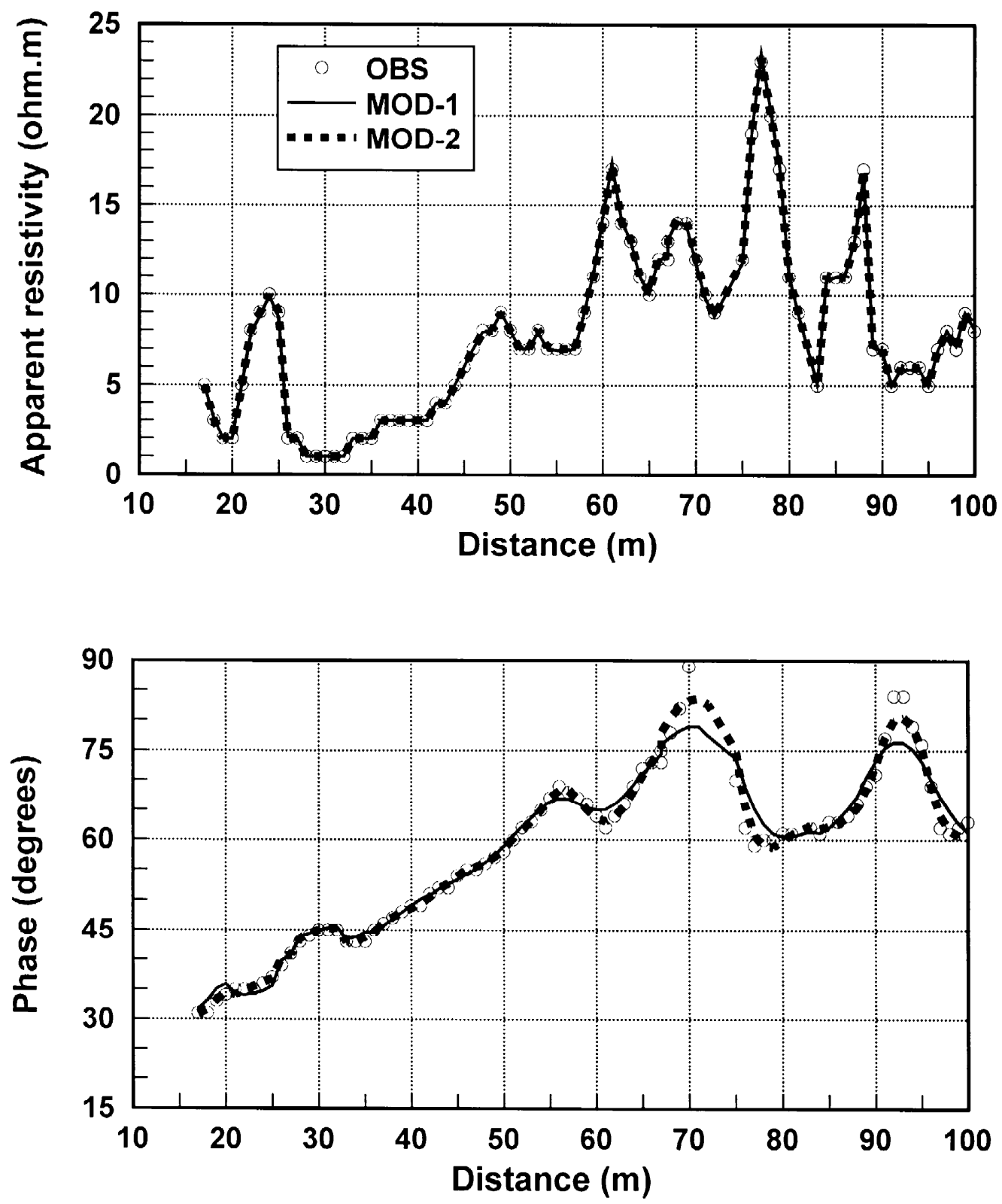

Fig. 11. Waste-site example: VLF- $R$ measurements (symbols) obtained between 17 and 100 $\mathrm{m}$ along profile. Measurement separation is $1 \mathrm{~m}$ and frequency is $16 \mathrm{kHz}$. The field data are compared with the responses of two inversion models: Model 1 (solid line) has an rms misfit of $5 \%$ and Model 2 (dash line) has an rms misfit of $3.6 \%$ assuming $2 \%$ data errors. 
a) $\quad$ rms misfit $=5 \%$

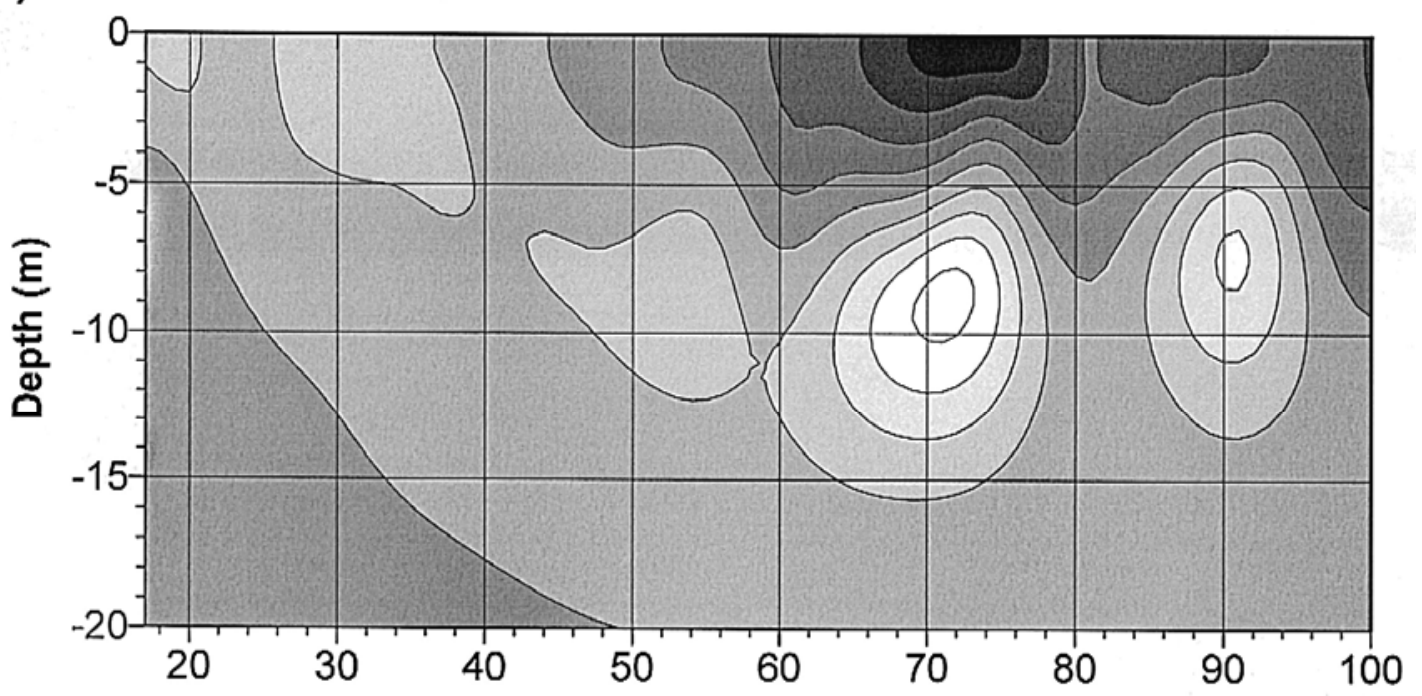

b) $\quad$ rms misfit $=3.6 \% \quad$ Distance $(\mathrm{m})$
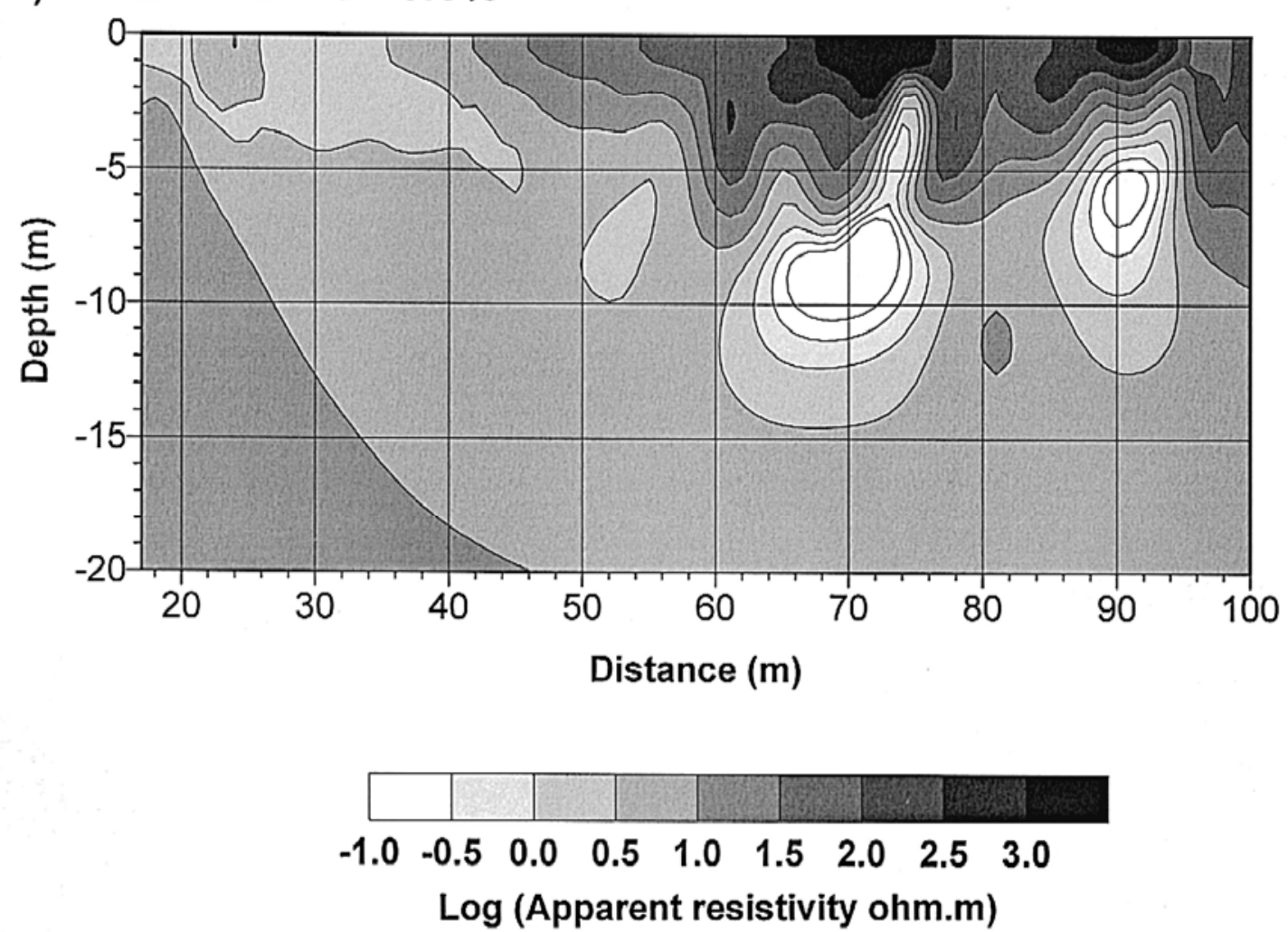

Fig. 12. Waste-site field example: Two resistivity models obtained by inverting the VLF- $R H-$ polarisation mode data shown in Fig. 11. The rms misfits are (a) $5 \%$ and (b) $3.6 \%$. Crosssections are contoured using the logarithm of resistivity. Vertical exaggeration $=2$. 